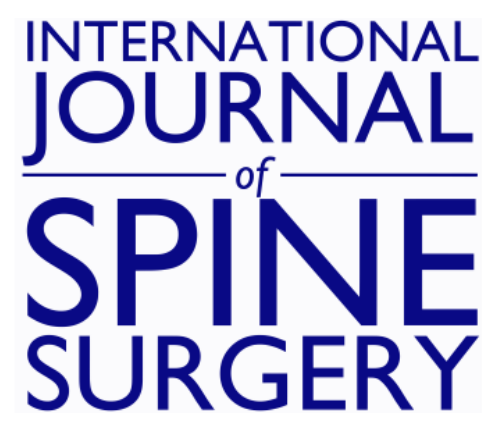

\title{
Modified Muscle-Sparing Paraspinal Approach for Stabilization and Interlaminar Decompression: A Minimally Invasive Technique for Pedicle Screw-Based Posterior Nonfusion Stabilization
}

Neel Anand, Eli M. Baron and Robert S. Bray, Jr.

Int J Spine Surg 2008, 2 (1) 40-42

doi: https://doi.org/10.1016/SASJ-2007-0120-MIS

http://ijssurgery.com/content/2/1/40

This information is current as of April 26, 2023.

Email Alerts Receive free email-alerts when new articles cite this article. Sign up at: http://ijssurgery.com/alerts 


\title{
Modified Muscle-Sparing Paraspinal Approach for Stabilization and Interlaminar Decompression: A Minimally Invasive Technique for Pedicle Screw-Based Posterior Nonfusion Stabilization
}

\author{
Neel Anand, MD, Eli M. Baron, MD, and Robert S. Bray, Jr., MD
}

\begin{abstract}
Introduction

Though Wiltse developed the paraspinal muscle-splitting approach to the spine, the exact location of where and how to split the paraspinal musculature when performing this approach remains unclear. This type of approach may be particularly useful for posterior nonfusion stabilization as significantly less damage occurs with this approach than with a muscle-stripping approach.
\end{abstract}

\begin{abstract}
Methods
We use the term "modified muscle-sparing approach" to describe our technique for following the natural cleavage plane between the multifidus and longissimus muscles to access the spine. We review the rationale behind this methodology and describe technical aspects of this approach and also demonstrate the technique on video.

Results

We use this technique routinely for our posterior nonfusion pedicle screw stabilization approach.

Conclusions

The modified muscle-sparing approach is a useful approach for insertion of pedicle screw-based posterior nonfusion stabilization. The approach can be readily performed with little blood loss and with little muscle damage. Decompression can also be performed through the same incision if needed.
\end{abstract}

Key Words: MIS, muscle-sparing approach, posterior nonfusion stabilization. SAS Journal. Winter 2008. 2:40-42. DOI: SASJ2007-0120-MIS

\section{INTRODUCTION}

Wiltse popularized the paraspinal sacrospinalis-splitting approach to the lumbar spine. ${ }^{1,2} \mathrm{He}$ described the approach as passing "trans-sacrospinalis." The sacrospinalis is split about two-finger breadths lateral to the midline. He further commented, "The muscle fibers do not split cleanly since at this level they run in various directions." He believed the advantage of the approach was that it was a more direct route to the transverse processes and facets of the lumbar spine with less bleeding than through midline approaches.

However, the location of the sacrospinalis muscle requiring splitting, despite Wiltse's descriptions, is unclear. Vialle et al. thought this to be the natural cleavage plane between the multifidus and the longissimus parts of the sacrospinalis muscle based on cadaveric studies. ${ }^{3}$ We originated the term "modified muscle-sparing approach," where this plane is teased apart by using a Langenbeck elevator to gently pull the fibers of the multifidus medially so this cleavage plane can be clearly visualized. ${ }^{4}$

\section{MATERIALS AND METHODS}

The patient is positioned prone on a Jackson Table with the legs extended to maximize lordosis. (See attached demonstration video.) Anteroposterior fluoroscopy is then used to localize and mark the lateral border of the pedicles to be instrumented. The dots are then connected to mark the paraspinal incision. This results in the paraspinal incision being about 2 to $2.5 \mathrm{~cm}$ lateral to the midline and not 4 to $5 \mathrm{~cm}$ lateral to the midline as traditionally described. ${ }^{5}$

The skin and subcutaneous tissue is incised, followed by clear identification of the lumbodorsal fascia. The fascia is then incised in line with the incision, and a Weitlaner retractor is placed on either edge of the fascia to open the intermuscular plane. By gently teasing the muscle fibers using a Langenbeck elevator, a clear plane can be identified between the multifidus medially and the longissimus laterally. Often fat can be identified within this plane to further delineate it. The muscles are then meticulously teased apart in a relatively avascular plane all the 


\section{Video 1.}

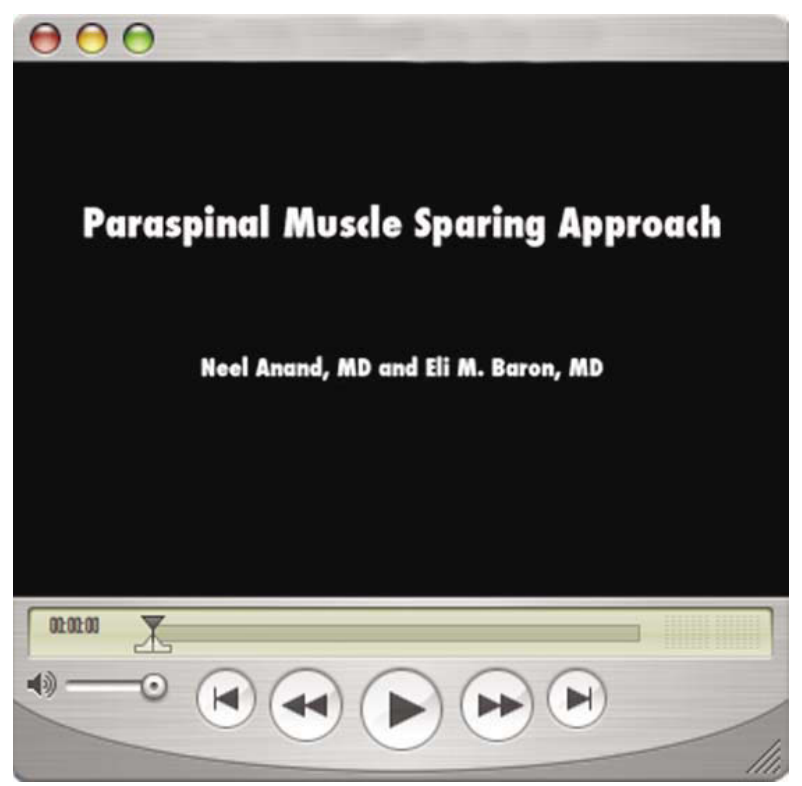

Click on the image above to download and view the video.

way down to the transverse processes, which can then be palpated with the surgeon's finger. A narrow-blade McCullough retractor is then placed with a slightly longer blade on the transverse process and a slightly shorter blade over the facet, retracting the multifidus medially and the longissimus laterally, resulting in exposure of the intermuscular plane down to the transverse process. Lateral fluoroscopy is then taken to confirm the level by placing a marker on the transverse process.

Next, the dorsal surface of the transverse process is exposed with the monopolar cautery. Great care is taken to avoid the stripping of any muscle of the sides or tip of the transverse process. This exposure is carried medially on the transverse process until the mamillary process and the lateral edge of the superior facet are identified. Extreme care is again taken not to strip the facet of any capsule or muscle attachments. Once the mamillary process is delineated, a pilot hole is drilled with a high-speed burr, and a gearshift is used to cannulate the pedicle and vertebral body, thus furnishing a channel for pedicle screw placement. The direction and position is confirmed with fluoroscopy, and the walls of the channel are inspected with a ball-tipped probe. A pedicle screw is then placed.

In similar fashion, the next transverse process is exposed by moving the retractor to the next level, and the pedicle screw is placed. The stabilizing device can then be placed, connecting the pedicle screws by moving the retractor between the pedicle screws maintaining the intermuscular plane while visualizing both screws. We believe that maintaining the retractors in one place for as short a time as possible minimizes any undue pressure on the muscle, thereby decreasing muscle ischemia and related problem. ${ }^{6-11}$ After the instrumentation is in place the lumbodorsal fascia is closed on both sides.
At this time, if decompression is indicated, the skin incision is moved medially, and the spinous processes can easily be palpated. A midline fasciotomy is then made, and subperiosteally the multifidus is gently reflected to expose the interlaminar space. A McCullough retractor is then used to retract the multifidus with a narrow blade laterally and a post medially on the interspinous ligament. The level is confirmed, and a laminotomy and foraminotomy can then be performed in standard fashion using a microscope or magnifying loupes. If bilateral decompression is desired the multifidus can be reflected similarly on the opposite side, or contralateral decompression can be carried out from the same side. We prefer the latter technique whereby access is obtained to the opposite side by tilting the operating table away from the surgeon and angling the operating microscope. ${ }^{12-16} \mathrm{~A}$ high-speed burr is then used to shave the undersurface of the spinous process, followed by curettes and Kerrison rongeurs to remove the ligamentum flavum centrally and on the opposite side all the way to the opposite pedicle. The foramen on the opposite side can similarly be followed out and decompressed, thereby achieving bilateral foraminal, lateral recess, and central decompression. The midline fasciotomy is then closed, followed by subcutaneous tissue and skin closure in layers with interrupted absorbable sutures.

\section{RESULTS}

The benefits of a minimally disruptive approach to spinal stabilization may be less damage to the paraspinal musculature, theoretically resulting in improved outcomes. We noted improvements in treatment intensity scores in patients undergoing posterior nonfusion stabilization via the musclesparing approach versus those undergoing conventional midline exposure. ${ }^{4}$

Paraspinal muscle damage seen after midline, muscle-stripping approaches has been described by numerous authors. ${ }^{6-11,17}$ Increased levels of inflammatory mediators were shown in patients undergoing conventional microdiscectomy versus minimally invasive microdiscectomy. ${ }^{18}$ In addition, increased muscular edema was demonstrated by magnetic resonance imaging in the paraspinal muscles of patients undergoing the midline muscle-stripping approach for open fusion versus those undergoing surgery with a minimally invasive approach. ${ }^{19}$

Panjabi discussed the concept of the neutral zone in the lumbar spine. He noted this to be a region of intervertebral motion around the neutral posture where little resistance is offered by the passive spinal column. ${ }^{20} \mathrm{He}$ also stated that the neutral zone appears to be a clinically important measure of spinal stability function. Injury or degeneration of the spinal column, or weakness of the muscles, may result in an increase of the neutral zone, which may lead to spinal instability or back pain. With an increase in the neutral zone, the stresses on the surrounding musculature increase in order to maintain the neutral zone. Panjabi thus hypothesized that the spinal stabilizing system adjusts so that the neutral zone remains within certain physiological thresholds to avoid clinical instability. 
We believe that in nonfusion surgery maintaining the soft tissue and musculature surrounding the spinal segment may be much more important clinically than in fusion surgery in achieving segmental balance and maintaining the neutral zone within physiological limits. Thus, an approach such as the one described above, which maintains the integrity of the paraspinal musculature and soft tissue, may result in improved outcomes. The muscle-sparing approach, with specific reference to posterior nonfusion stabilization systems, also allows for placement of screws well away from the facet in a more lateral to medial trajectory. Nevertheless, the surgeon must be very careful when placing screws using this approach as facet violations may easily occur. Shah et al., ${ }^{21}$ in a review of patients undergoing lumbar fusion with pedicle screws placed via the Wiltse approach, noted facet violations in $20-23 \%$ of the proximally placed pedicle screws

\section{CONCLUSIONS}

A modified muscle-sparing approach may be useful for placement of pedicle screws for posterior nonfusion stabilization. Decompression may be performed through the same incision. Theoretically, the benefits of such an approach include less blood loss, less muscle damage, and subsequently less pain than when midline approaches are performed. An additional advantage is the ability to optimally place pedicle screws via a more lateral to medial trajectory, allowing optimal placement of posterior nonfusion stabilization systems without violation of the facet capsule.

Neel Anand, MD, Eli M. Baron, MD, Robert S. Bray, Jr., MD

From the Institute for Spinal Disorders, Cedars Sinai Medical Center, Los Angeles, California

The authors have no financial interest in relation to the device used in this study.

Address correspondence and reprint requests to Neel Anand, MD, CedarsSinai Institute for Spinal Disorders, 444 S. San Vicente Blvd, Ste 800, Los Angeles, California 90048 (email: Neel.Anand@ cshs.org)

This manuscript was submitted October 23, 2007, and accepted for publication December 6, 2007.

\section{REFERENCES}

1. Wiltse LL, Bateman JG, Hutchinson RH, Nelson WE. The paraspinal sacrospinalis-splitting approach to the lumbar spine. J Bone Joint Surg Am. 1968;50(5):919-926.

2. Wiltse LL. The paraspinal sacrospinalis-splitting approach to the lumbar spine. Clin Orthop Relat Res. 1973(91):48-57.

3. Vialle R, Wicart P, Drain O, Dubousset J, Court C. The Wiltse paraspinal approach to the lumbar spine revisited: an anatomic study. Clin Orthop Relat Res. 2006;445:175-180.

4. Anand N, Baron EM, Bray RS. Benefits of the paraspinal musclesparing approach versus the conventional midline approach for posterior nonfusion stabilization: Comparative analysis of clinical and functional outcomes. SAS Journal. 2007;1(3):63-67.
5. Tannoury C, Anderson DG, Vaccaro AR, Albert TJ. Posterior Far Lateral Disk Herniation. In: Vaccaro AR, Baron EM, eds. Operative Techniques Spine Surgery. 1st ed. Philadelphia: Saunders Elsevier; 2007:325-333.

6. Gejo R, Matsui H, Kawaguchi Y, Ishihara H, Tsuji H. Serial changes in trunk muscle performance after posterior lumbar surgery. Spine. 1999;24(10):1023-1028.

7. Suwa H, Hanakita J, Ohshita N, Gotoh K, Matsuoka N, Morizane A. Postoperative changes in paraspinal muscle thickness after various lumbar back surgery procedures. Neurol Med Chir (Tokyo). 2000;40(3):151-154; discussion 154-155.

8. Rantanen J, Hurme M, Falck B, et al. The lumbar multifidus muscle five years after surgery for a lumbar intervertebral disc herniation. Spine. 1993;18(5):568-574.

9. Mayer TG, Vanharanta H, Gatchel RJ, et al. Comparison of CT scan muscle measurements and isokinetic trunk strength in postoperative patients. Spine. 1989;14(1):33-36.

10. Kawaguchi Y, Yabuki S, Styf J, et al. Back muscle injury after posterior lumbar spine surgery. Topographic evaluation of intramuscular pressure and blood flow in the porcine back muscle during surgery. Spine. 1996;21(22):2683-2688.

11. Kawaguchi $\mathrm{Y}$, Matsui $\mathrm{H}$, Tsuji $\mathrm{H}$. Back muscle injury after posterior lumbar spine surgery. Part 2: Histologic and histochemical analyses in humans. Spine. 1994;19(22):2598-2602.

12. Getty CJ, Johnson JR, Kirwan EO, Sullivan MF. Partial undercutting facetectomy for bony entrapment of the lumbar nerve root. The Journal of Bone and Joint Surgery. 1981;63-B(3):330-335.

13. Oertel MF, Ryang YM, Korinth MC, Gilsbach JM, Rohde V. Longterm results of microsurgical treatment of lumbar spinal stenosis by unilateral laminotomy for bilateral decompression. Neurosurgery. 2006;59(6):1264-1269; discussion 1269-1270.

14. Spetzger U, Bertalanffy H, Naujokat C, von Keyserlingk DG, Gilsbach JM. Unilateral laminotomy for bilateral decompression of lumbar spinal stenosis. Part I: Anatomical and surgical considerations. Acta Neurochir (Wien). 1997;139(5):392-396.

15. Spetzger U, Bertalanffy H, Reinges MH, Gilsbach JM. Unilateral laminotomy for bilateral decompression of lumbar spinal stenosis. Part II: Clinical experiences. Acta Neurochir (Wien). 1997;139(5):397-403.

16. Young S, Veerapen R, O'Laoire SA. Relief of lumbar canal stenosis using multilevel subarticular fenestrations as an alternative to wide laminectomy: preliminary report. Neurosurgery. 1988;23(5):628-633.

17. Sihvonen T, Herno A, Paljarvi L, Airaksinen O, Partanen J, Tapaninaho A. Local denervation atrophy of paraspinal muscles in postoperative failed back syndrome. Spine. 1993;18(5):575-581.

18. Sasaoka R, Nakamura H, Konishi S, et al. Objective assessment of reduced invasiveness in MED. Compared with conventional one-level laminotomy. Eur Spine J. 2006;15(5):577-582.

19. Stevens KJ, Spenciner DB, Griffiths KL, et al. Comparison of minimally invasive and conventional open posterolateral lumbar fusion using magnetic resonance imaging and retraction pressure studies. J Spinal Disord Tech. 2006;19(2):77-86.

20. Panjabi MM. The stabilizing system of the spine. Part II. Neutral zone and instability hypothesis. J Spinal Disorders. 1992;5(4):390-396; discussion 397.

21. Shah RR, Mohammed S, Saifuddin A, Taylor BA. Radiologic evaluation of adjacent superior segment facet joint violation following transpedicular instrumentation of the lumbar spine. Spine. 2003;28(3):272-275. 